\title{
Comparison Laboratory Methods for Detection of Hookworms Infection
}

\author{
Merina Panggabean ${ }^{1}$, Lambok Siahaan ${ }^{2}$, Yoan Carolina Panggabean ${ }^{3}$ \\ ${ }^{1.2 .3}$ Department of Parasitology, Faculty of Medicine, University Sumatera Utara, Indonesia \\ mer.pgb@gmail.com \\ lamboksiahaan_fkusulyahoo.com \\ carolina_yoaneyahoo.com
}

\begin{abstract}
Intestinal parasitic infections are globally endemic in the world. In Indonesia, intestinal parasitic infections particularly helminthes is one of the public health problems. It can cause malnutrition and anemia so can be disturbing growth and development children. Intestinal parasitic infections with soil-transmitted helminths (STH) such as Ascaris lumbricoides, Trichuris trichiura and hookworms (Necator americanus and Ancylostoma duodenale) diagnosed by detection of helminth eggs in stool samples. Stool samples commonly examine by using microscopic with conventional techniques as direct wet smear stain like Lugol stain, sedimentation methods like formol ether concentration (FEC). Stool examination for hookworm with conventional techniques often miss opportunity in laboratory. Therefore we used modified Harada Mori culture to detect hookworms infection. The objective of this study was to compare modified Harada Mori culture method and others laboratory methods like direct wet smear Lugol stain and FEC to detect hookworm infections. This research done by cross-sectional method in Sub regency Tanjung Tiram, Regency Batubara Province of Sumatera Utara. A total of 40 stool samples participants was immediately examined by modified Harada Mori culture, direct wet smear Lugol stain and FEC. The results showed that $8(20 \%)$ stool samples positive for hookworm from 40 samples were examined by modified Harada Mori culture and none hookworm for direct wet smear Lugol stain and FEC. Direct wet smear Lugol stain and FEC miss for hookworm if concentration is too low and also fragile of hookworm eggs. This research found that modified Harada Mori culture was most effective method for detection hookworms.
\end{abstract}

Keywords - Formol ether concentration, Harada Mori culture, Hookworm, Lugol stain, soil-transmitted helminths (STH).

\section{INTRODUCTION}

Infections caused by the human intestinal nematodes can be spread in tropical and subtropical regions with the largest number occurred in subSaharan Africa, the Americas, China and East Asia. Based on data from the World Health Organization, more than 1.5 billion people or $24 \%$ of the world's population is infected with the worm [1-2]. Indonesia has a prevalence of worm infection in some regency and cities in 2012 showed above $20 \%$ [3]. The infection is usually caused by soil- transmitted Helminths (STH) or worms are transmitted through by the soil. They are transmitted by eggs present in human faeces which in turn contaminate soil [1]. STH infections belong to the neglected tropical diseases (NTDs) that affect human populations in poorer regions of the world [4]. Their presence is a typical marker of poverty where access to sanitation and clean water is limited and, concomitantly, standards of hygiene are low [5]-[7]. There are four main species of STH; namely, Ascaris lumbricoides (roundworm), Trichuris trichiura (whipworm) and the hookworms (Ancylostoma duodenale and Necator americanus) [8].

Laboratory examination of feces to find the worm eggs play an important role to ensure the worm infection status of a person [9]. An accurate diagnosis of soil-transmitted helminthiasis is important for individual patient management, for drug efficacy evaluation and for monitoring control programmes [10]. Diagnosis infection STH is generally based on the detection of worm eggs or larvae in the faeces [11]. Some ways to diagnose STH infections are microscopically such as direct wet smear technique like Lugol stain, and Formol ether concentration (FEC). Diagnose must be sensitive and practical [9], [11].

Direct wet smear technique like Lugol stain is quick to prepare and inexpensive when compared with other methods but it can miss eggs of hookworms if concentration is too low [12]. Formol ether concentration method is the sedimentation technique normally used for detecting parasite infections, especially eggs and protozoan cysts with a high fat in stool samples [13]. There is need for increase probability of finding the parasite in the 
fecal samples to allow for accurate diagnosis, hence there is need to practice other methods. It has been that modified Harada Mori culture technique for detecting hookworms [14] [15]. The objective of this study was to campare direct wet smear Lugol stain, formol ether concentration (FEC) and modified Harada Mori to detect hookworm infections.

\section{MATERIALS AND METHODS}

This research done by cross-sectional method in Sub regency Tanjung Tiram, Regency Batubara Province of Sumatera Utara. A total of 40 stool samples participants in this study were immediately examined by modified Harada Mori culture, direct wet smear Lugol stain and formol ether concentration. A fecal container for collection and storage will be used. These containers will be labeled with identifiers including the name of the participants, sex, age, and the consistency of the stool.

The stool participants will place on a piece of paper for modified Harada Mori culture. Cut a narrow strip of filter paper and taper it slightly at one end. Smear 0.5 to $1 \mathrm{~g}$ of feces in the center of the strip. Then, add 3 to $4 \mathrm{~mL}$ of distilled water to a $15 \mathrm{~mL}$ plastic. Insert the filter paper strip into the plastic so that the tapered end is near the bottom of the plastic. Make sure that the water level should be slightly below the fecal spot. Afterwards, allow the tube to stand upright in a rack at room temperature. Add distilled water to maintain the original level. Kept the plastic for 10 days and check daily. Prepare a smear on a glass slide with a cover slip and examine.

After took stool samples for modified Harada Mori, stool samples added with formalin $10 \%$ and examine for Lugol stain [16] and FEC [17] at laboratory.

\section{RESULTS}

A total of 40 stool samples from participants of different age were included in this study. Among the $8(20 \%)$ stool samples modified Harada Mori culture positive for hookworms and none for Lugol stain and FEC (Table I).
TABLE I

DETECTION OF HOOKWORMS BY DIFFERENT METHODS

\begin{tabular}{|l|c|}
\hline Methods & $\begin{array}{l}\text { Amount Positive } \\
\text { Hookworms (\%) }\end{array}$ \\
\hline $\begin{array}{l}\text { Modified Harada Mori } \\
\text { culture }\end{array}$ & $8(20 \%)$ \\
\hline Lugol stain & 0 \\
\hline FEC & 0 \\
\hline
\end{tabular}

\section{DISCUSSION}

The differences in the method of hookworms diagnosis across the selected studies showed modified Harada Mori most effective. The results showed that prevalence of hookworm infections was $20 \%$. Hookworm was more prevalent in rural areas. This study showed that all Ancylostoma duodenale. In contrast, study Dhaka showed that Necator americanus was the dominant hookworm species in the study [18].

Direct wet smear Lugol stain have advantage is quick to prepare compare two other methods. But have disadvantage if concentration is too low or if too much debris or fat is present [12]. In this study may be concentration eggs hookworm to low, that is why no found eggs hookworm.

Hookworm eggs in the FEC method missed, because the shell of eggs hookworm is very thin and fragile. So that the time to do concentration when centrifuged the stool samples, it eggs shells was broken. That is why missed eggs as microscopically in this method.

In method modified Harada Mori culture, stool samples was placed directly to Harada Mori culture filter paper strip into the plastic for growth of hookworm larvae. It is indicates the participants was infected with hookworms if found larvae hookworm after 10 days culture. Similar study by Okolie (2007) in Nigeria showed that Harada Mori culture was more effective to detect hookworm than routine wet film microscopy. The methods particularly simple, cost cheaper and requires minimum labour and skill. It is recommended for field and epidemiology studies in hookworm endemic in the world [19].

\section{REFERENCES}

[1] World Health Organization. 2016. Soil transmitted infection http://www.who.int/mediacentre/factsheets/fs366/en/

[2] S. Knop, N Salim, T. Schindler, K. Voules, J. Rothen, and O. Lweno. Diagnostic accuracy of Kato-Katz, FLOTAC, Baermann, and PCR 
methods for detection of light-intencity hookworm and Strongyloides stercoralis infection in Tanzania. Am J. Trop. Med. Hyg, 90: 535-545. 2014.

[3] Directorate General of PP \& PL Kemenks RI. 2013. Disease Control and Environmental Health in 2013. Ministry of Health of the Republic Indonesia. Jakarta. 112-113

[4] R.I. Pullan, and S.J. Brooker. The global limits and population at risk of soil-transmitted helminth infections in 2010. Parasit Vectors. $5(1): 81.2012$

[5] P.J. Hotez, A. Fenwick, L. Savioli, and DH. Molyneux. Rescuing the bottom billion through control of neglected tropical diseases. Lancet. 373 (9674):1570-5. 2009

[6] S.A. Esrey, J.B. Potash, L.Roberts, and C. Shiff. Effects of improved water supply and sanitation on ascariasis, diarrhoea, dracunculiasis, hookworm infection, schistosomiasis, and trachoma. Bull World Health Organ. 69(5): 609-621. 1991

[7] K. Ziegelbauer, B. Speich, D. Mäusezahl, R. Bos, J. Keiser, and J Utzinger. Effect of sanitation on soil-transmitted helminth infection systematic review and meta-analysis. PLoS Med.. 9(1): e1001162. 2012.

[8] J. Bethony, S. Brooker, M. Albonico, S.M. Geiger, A. Loukas, and D. Diemert, et al. Soil-transmitted helminth infections: ascariasis, trichuriasis, and hookworm. Lancet.. 367(9521):1521-32. 2006.

[9] B. Nikolay, S.J. Brooker, and Pullan, R.I. Sensitivity of diagnostic test for human soil-transmitted helminth infections: a meta-analysis in the absence of a true gold standard. Int J Parasitol. 44 (11). 765-774. 2014

[10] B. Speich, S.M. Ali, S.M. Ame, M. Albonico, J. Utzinger, and J. Keiser. Quality control in the diagnosis of Trichuris trichiura and Ascaris lumbricoides using the Kato-Katz technique: experience from three randomised controlled trials. Parasit Vectors. 5(8):82. 2015.

[11] S. Taye. Comparison of Kato-Katz and formol ether concentration methods for the diagnosis of intestinal helminthic infection among school children of Wonji Shoa town, Eastern Ethiopia: a school based cross sectional study. Am J of Health Research. 2 (5). 271-274. 2014.

[12] V. Oguoma, and C Ekwunife. The Need For A Better Method: Comparison Of Direct Smear And Formol-Ether Concentration Techniques In Diagnosing Intestinal Parasites. The Internet Journal of Tropical Medicine. 3(2). 1-6. 2007

[13] S. Uga, K. Tanaka and N Iwamoto. Evaluation and modification of the formalin ether sedimentation technique. Tropical Biomedicine. 27 (2). 177-184. 2010.

[14] M. Muscat, K.Z. Mamun, S.Tabassum, A.A. Ahmed, P. Shears. Environmental risk factors and intestinal parasitic carriage in Bangladesh. Journal of Dhaka Medical College. 13(1): 1-7. 2004.

[15] D. Goodman, H.J. Haji, Q.D. Bickle, R.J. Stoltzfus, J.M. Tielsch, M Ramsan, L. Savioli, M. Albonico. A comparison of methods for detecting the eggs of Ascaris, Trichuris and hookworm in infant stool, and the epidemiology of infection in Zanzibari infants. Am J Trop Med Hyg. 76(4): 725-731. 2007.

[16] Garcia LS, Bruckner DA. 1988. Diagnostic medical parasitology. New York, Elsevier.

[17] R.S. Anecimo, K.A.A. Tonani, B.M. Fregonesi, A.P. Mariano, M.D.B Ferrasino, T.M.B. Trevilato, et al. Adaptation of Ritchie's method for parasites diagnosing with minimization of chemical products. Interdisciplinary Perspectives on Infectious Diseases. 2012.

[18] S. B. Shahid, A. Wazib, A. Chowdhury, S.M. Shamsuzzaman, and K.Z Mamun. Identicifation of Hookworm Species in Stool By Harada Mori Culture. Bangladesh J Med Microbiol. 04 (02). 03-04. 2010.

[19] N.J.C. Okolie. Application of Haradi Mori's culture method for differentiating hookworm species in two major cities of Southern Nigeria. Research Journal of Medical Sciences. 1(1): 16-20. 2007. 